\title{
Toward carbon nanotube-based imaging agents for the clinic
} Authors: Mayra Hernández-Rivera, Nicholas G. Zaibaq, and Lon J. Wilson*

Affiliations: Department of Chemistry and Smalley-Curl Institute, Rice University, Houston, TX, USA *Corresponding author: L. J. Wilson, Department of Chemistry, MS\#60 Rice University, P. O. Box 1892 Houston, TX, 77251-1892, USA; Tel: 713-348-3476; Email: durango@ rice.edu Other authors: M. Hernández-Rivera (mh28@ rice.edu); N. G. Zaibaq (ngz1@ @rice.edu)

\begin{abstract}
Among the many applications for carbon nanotubes (CNTs), their use in medicine has drawn special attention due to their potential for a variety of therapeutic and diagnostic applications. As progress toward clinical applications continues, monitoring CNTs in vivo will be essential to evaluate their biodistribution, potential toxicity, therapeutic activity, and any physiological modifications that the material may induce in specific tissues. There are many different imaging modalities to visualize and track CNTs in vivo, yet only a few are full-body penetrating, a central characteristic that widens their clinical utility. In order to visualize CNTs, chemical modification is often required for the material to be used as a platform to carry imaging agents compatible with one or more of the clinical imaging techniques. Here, we focus on the most recent work involving the use of CNTs as imaging agents for the non-invasive, full-body penetrating clinical modalities of MRI, PET, SPECT, and X-ray CT. The synthesis and modification of the CNT materials are discussed, as well as relevant preclinical studies.
\end{abstract}

Keywords: carbon nanotubes; clinical imaging; MRI; PET; SPECT; X-ray CT

Abbreviations: acetylacetone (acac); carbon nanotubes (CNTs); computed tomography (CT); contrast agent (CA); diethylenetriaminepentaacetic dianhydride (DTPA); doxorubicin (DOX); extended X-ray absorption fine structure (EXAFS); Gadonanotube (GNT); hexafluoroacetylacetone (hfac); high pressure carbon monoxide (HiPCO); high resolution transmission electron microscopy (HR-TEM); inductively-coupled plasma mass spectrometry (ICP-MS); intravenous (i.v.); inversion time (Ti); magnetic resonance imaging (MRI); multiwalled carbon nanotubes (MWCNTs); p-carboxyphenyldiazonium (PCP); percent injected dose per gram of tissue (\% ID/g); phosphate buffered saline (PBS); poly(allylamine hydrochloride) (PAH); poly(diallydimethylammonium chloride) (PDDA); polyethylene glycol (PEG); positron emission tomography (PET); scanning transmission electron microscopy (STEM); single-photon emission computed tomography (SPECT); single-walled carbon nanotubes (SWCNTs); superparamagnetic iron oxide nanoparticles (SPIONs); 1,4,7,10-tetraazacyclododecane-1,4,7,10tetraacetic acid (DOTA); 2,2,6,6,-tetramethyl-3,5-heptanedione (thd); Tesla (T); transmission electron microscopy (TEM); ultra-short SWCNTs (US-SWCNTs) 


\section{Introduction}

Among the many nanoparticles currently under investigation, carbon nanotubes have been and continue to be a key material for their unique properties, cost effectiveness, and extreme diversity of applications. Carbon nanotubes (CNTs) can be described as graphene sheets that are rolled in a cylindrical shape and have different electrical and optical properties depending on the axis about which they are rolled, which is called chirality or the "twist" of the nanotube. The different CNT chiralities include the armchair structure, in which the C-C bonds are perpendicular to the tube axis; the zig-zag structure, in which the $\mathrm{C}-\mathrm{C}$ bonds are parallel to the tube axis; and the chiral structure, in which the $\mathrm{C}-\mathrm{C}$ bonds lie at an angle with respect to the tube axis $[1,2]$. CNTs are either single-walled (SWCNTs) with a diameter around 1-2 nm, or multiwalled (MWCNTs), which are composed of 2-30 concentric SWCNTs with an outer diameter ranging from 10-100 $\mathrm{nm}$. Some of the methods that are generally used to produce CNTs are arcdischarge, laser-ablation, and chemical vapor deposition, including the high-pressure carbon monoxide (HiPCO) synthesis. These processes usually occur in the presence of transition metal $(\mathrm{Co}, \mathrm{Fe}, \mathrm{Ni})$ or rare earth $(\mathrm{Gd}, \mathrm{Y})$ catalysts, which remain in the pristine CNT product [3-9]; significant progress has been accomplished in the removal of trace amounts of these catalysts [913], although more work is currently underway. Since their discovery [14], CNTs have been of great interest because of their unique structural and chemical properties, such as their high tensile strength, high aspect ratio, and the capability to be chemically functionalized, while remaining relatively inert [15-18]. This interest has led to CNTs being used in a variety of applications in electronics [19,20], material composites [21], energy [22], catalyst supports [23,24], and particularly those in the medical field [25-27]. Within the emerging field of nanomedicine, CNTs have been investigated as drug delivery vectors [28,29], therapeutic agents exploiting microwave-, photo-, or radiofrequency-induced thermal effects [30-33], scaffolds for tissue engineering [34], and diagnostic imaging agents [35,36].

For diagnostic and therapeutic applications, it is essential to determine the CNT biodistribution and pharmacokinetic profile to study the biological effects of the material on specific tissues. To this end, researchers have used a wide range of imaging modalities that rely on the intrinsic properties of CNTs. These techniques include Raman scattering [37], high optical and near infrared (NIR) absorbance, and photoluminescence [38-40], photoacoustic [41-44], thermoacoustic [45], and echogenic properties [46]. However, some of these imaging techniques suffer from penetration depth limitations, poor spatial resolution, or poor soft-tissue contrast $[47,48]$. To combat these limitations, CNTs may be employed as a scaffold or capsule for 
radionuclides or ions that are used for the noninvasive, full-body penetrating clinical modalities, such as magnetic resonance imaging (MRI), single-photon emission computed tomography (SPECT), positron emission tomography (PET), and X-ray computed tomography (X-ray CT) (see Figure 1).

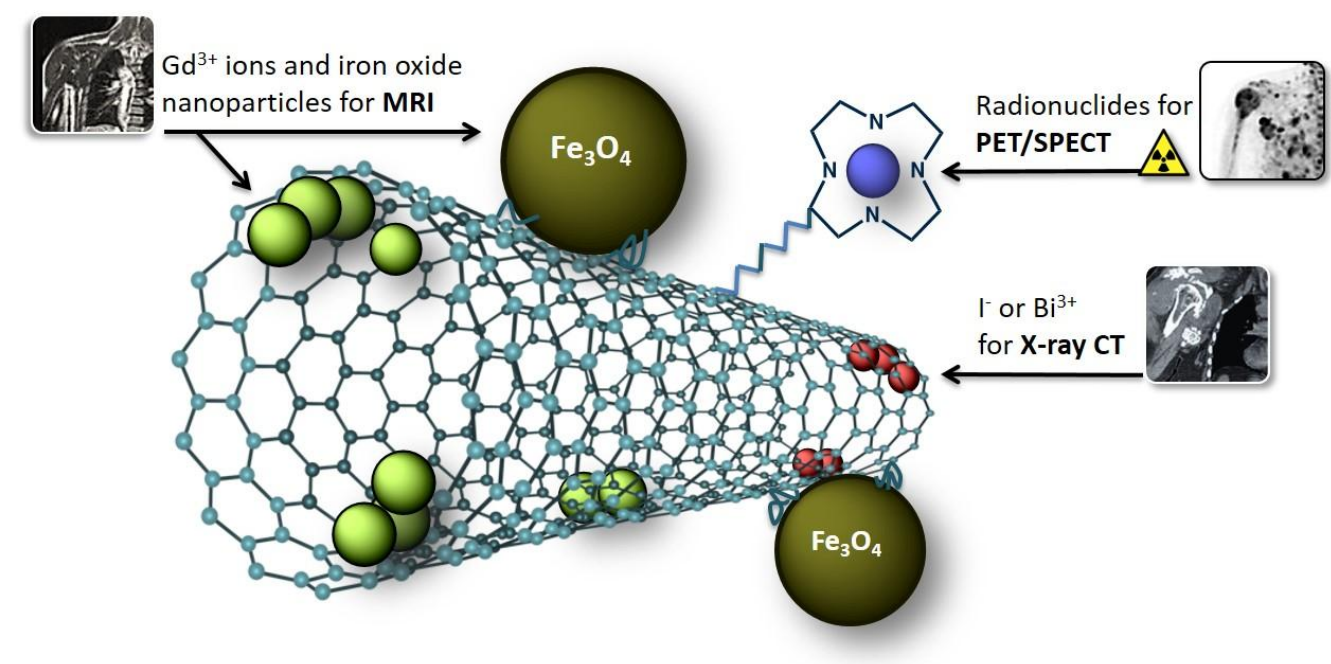

Figure 1: Schematic of the versatile CNT platform. Various ways to modify CNTs: attaching chelated ions or nanoparticles, such as superparamagnetic iron oxide nanoparticles (SPIONs), to the outer surface of the material or loading other agents or ions within the hollow interior of the material.

While common imaging contrast agents (CAs) generally are not able to cross the cell membrane, the use of CNTs allows for these agents to be delivered intracellularly for cell tracking and sometimes selectively with the use of biological targeting moieties. Packaging the imaging agents onto or inside the CNTs enables them to be internalized by cells [49] without the need of cytotoxic transfection agents [50,51]. However, the highly hydrophobic nature of CNTs also prohibits their suspension in aqueous media, requiring covalent or non-covalent functionalization techniques to produce biocompatibility and high aqueous suspendability (see Figure 2). Several reviews discussing extensively the different methods for CNT functionalization have been previously published [52-54], as well as reviews on the use of CNTs for imaging $[35,36,55-57]$; however, the rapid growth in the field constantly prompts an updated discussion of current findings. For this reason, this review focuses primarily on recent clinically relevant work involving exclusively non-invasive full-body penetrating techniques reported within the past five years. 
A

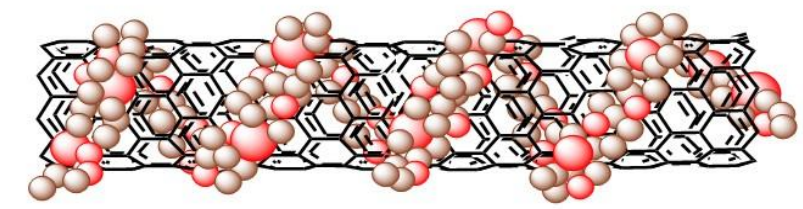

B

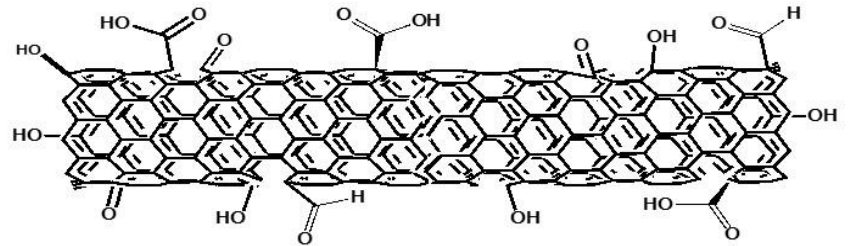

C
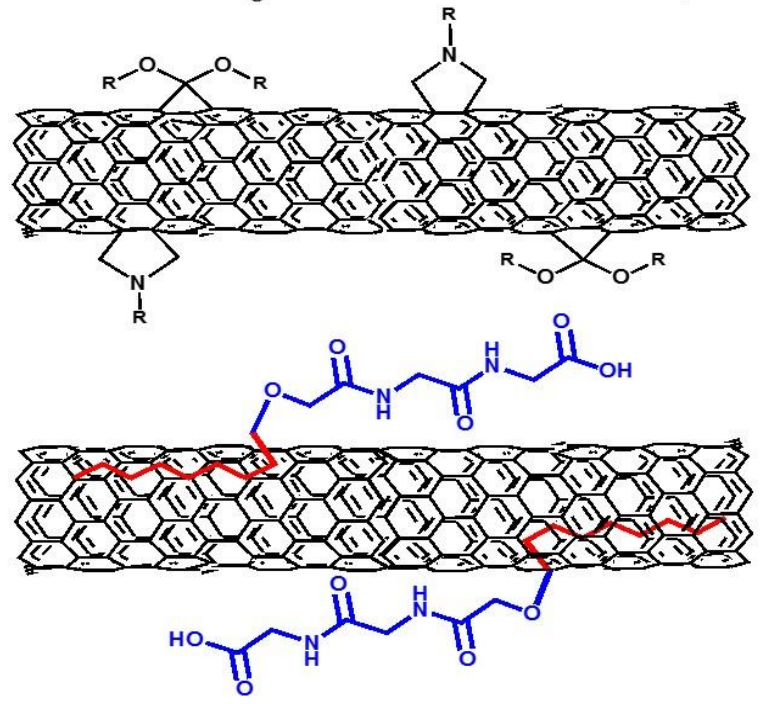

Figure 2: Common CNT functionalization techniques. Common strategies to render CNTs watersuspendable including (A) non-covalent functionalization with surfactants that wrap the CNT according to van der Waals forces, (B) oxidation of the CNT surface using strong acids, (C) covalent functionalization of the surface, where $\mathrm{R}$ is usually a peptide chain or another hydrophilic moiety (Note: 1,3-dipolar cycloaddition of azomethine ylides and cyclopropanation are typically performed separately on different materials), and (D) non-covalent functionalization with amphiphilic peptides (blue) where a hydrophobic chain (red) interacts with the material by van der Waals forces.

\section{CNT-based Agents for MRI}

Among the imaging techniques used in the clinic, MRI offers the advantage of highquality anatomical images with high spatial resolution without the use of ionizing radiation. Instead, MRI utilizes a high-intensity magnetic field that aligns the nuclear magnetization of hydrogen atoms in water molecules within the body, taking advantage of the difference in water concentration among tissues to produce images. Common MRI CAs are chemical compounds containing a chelated paramagnetic metal ion (such as $\mathrm{Gd}^{3+}, \mathrm{Mn}^{2+}$, etc.) with larger effects on $T_{1}$ shortening (spin-lattice relaxation agents), or superparamagnetic materials such as iron oxide 
nanoparticles with larger effects on $T_{2}$ shortening (spin-spin relaxation agents), where $T_{1}$ and $T_{2}$ are the proton relaxation times. The theoretical basis for the relaxivity of paramagnetic and superparamagnetic agents has been extensively described in the literature [58-62]. In order to produce an MRI-active CNT CA, a paramagnetic or superparamagnetic agent must be conjugated to or encapsulated within the CNT platform.

\subsection{Gadolinium-based Contrast Agents}

The first CNT-based MRI CA containing $\mathrm{Gd}^{3+}$ was reported in 2005 by Sitharaman et al., and was termed the "Gadonanotube" or GNT $[63,64]$. The CA consisted of ultra-short (20-80 $\mathrm{nm}$ ) single-walled carbon nanotubes (US-SWCNTs) loaded with $\mathrm{Gd}^{3+}$ ion clusters (3-4\% Gd by weight, see Figure $3 \mathrm{~A}$ and $3 \mathrm{~B}$ ). GNTs displayed 40 to 90 times superior relaxivity values compared to the clinically used MRI CA Magnevist ${ }^{\circledR}$. Furthermore, the $\mathrm{Gd}^{3+}$ ion cluster are so tightly contained by the CNT platform that the ions do not leak out of the CNTs under biological conditions [65], which is critical for clinical applications given the high toxicity of free $\mathrm{Gd}^{3+}$ [66]. Usually, a $0.17 \%$ Pluronic $^{\circledR}$ F-108 solution is used to suspend the GNTs in an aqueous medium for in vitro studies. In subsequent reports, GNTs were used to label macrophage cells [67], mesenchymal stem cells (see Figure 3C and 3D) [68,69], and HeLa cells [70]. In all cases, GNTs localized in the cytoplasm of the cell, delivering about $10^{9} \mathrm{Gd}^{3+}$ ions per cell. In another study, GNTs were covalently derivatized with ${ }_{\mathrm{D}, \mathrm{L}}$-serine amino acid substituents to produce water-suspendable ( $2 \mathrm{mg} / \mathrm{mL}$ ) "ser-GNTs," which were then used to label MCF-7 human breast cancer cells with no observable cytotoxic effects or morphologic changes [71].

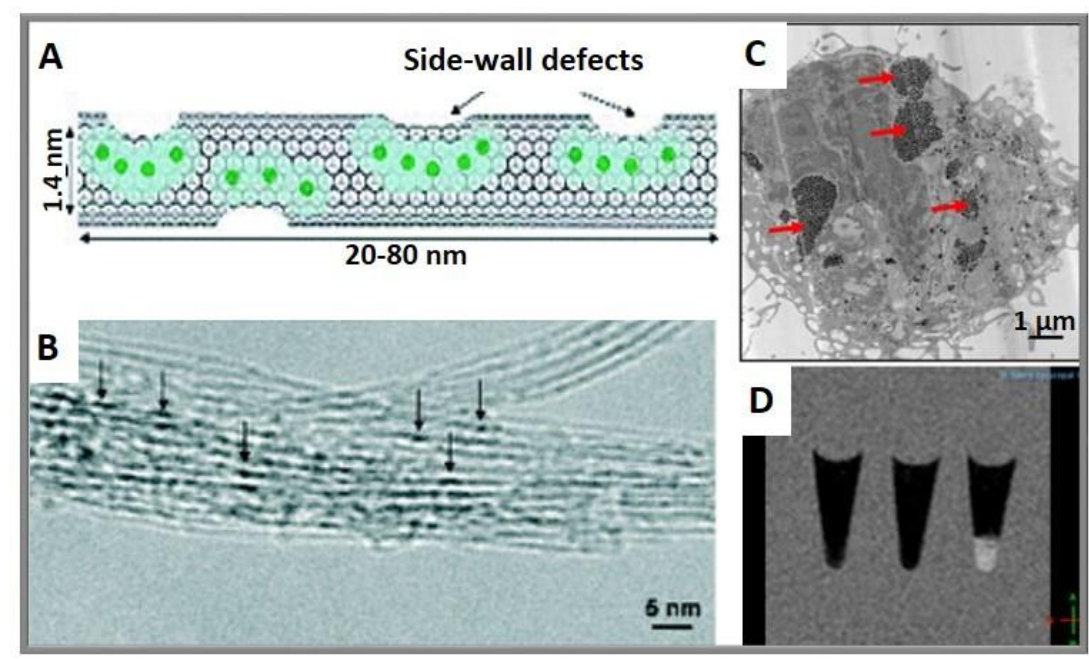

Figure 3: Gadonanotubes (GNTs) as an intracellular MRI CA. (A) Illustration of a single US-SWCNT loaded with $\mathrm{Gd}^{3+}$ ions (GNT). (B) High resolution transmission electron microscopy (HR-TEM) image of the bundled GNTs showing the $\mathrm{Gd}^{3+}$ clusters (arrows) formed within the US-SWCNTs. (C) TEM image of 
a GNT-labeled MSC. Red arrows point to GNT aggregates in the cytoplasm of the cell. (D) $T_{1}$-weighted MR images at $1.5 \mathrm{~T}$ and $25^{\circ} \mathrm{C}$ of (left to right) unlabeled MSCs, Gd-DTPA (diethylenetriaminepentaacetic dianhydride)-labeled MSCs (for comparison), and GNT-labeled MSCs at $\mathrm{Ti}=500 \mathrm{~ms}$ ( $\mathrm{Ti}=$ inversion time). (A) and (B) adapted from ref. [63], Copyright (2005), with permission from Royal Society of Chemistry. (C) and (D) adapted from ref. [68], Copyright (2010), with permission from Elsevier.

In a follow-up to the original GNT report, three new Gd-based CAs, derived from confinement of three different gadolinium chelates within the cavities of the same US-SWCNTs were recently reported. The chelates $\mathrm{Gd}(\mathrm{acac})_{3} \cdot 2 \mathrm{H}_{2} \mathrm{O}, \mathrm{Gd}(\mathrm{hfac})_{3} \cdot 2 \mathrm{H}_{2} \mathrm{O}$, and $\mathrm{Gd}(\text { thd })_{3}(\mathrm{acac}=$ acetylacetone; $\mathrm{hfac}=$ hexafluoroacetylacetone; thd $=$ 2,2,6,6,-tetramethyl-3,5-heptanedione), were used to evaluate the effect of the number of water molecules coordinated to the $\mathrm{Gd}^{3+}$ ion $(q)$, which is one of the factors that influences the inner-sphere relaxivity of the CA [72]. In doing so, it was proven that the encapsulation of the free $\mathrm{Gd}^{3+}$ ions (non-chelated) provided a better MR outcome than the chelated ions, because the $\mathrm{Gd}^{3+}$ ions within the US-SWCNTs have a $q$ of approximately 3 , while the chelated ions have a $q$ value of 0 or 2 , depending on the chelate. The amount of Gd within the US-SWCNTs for each sample was reported to be 7.91, 4.45, and 7.73 wt. \% for the acac, hfac, and thd chelates, respectively. To further decipher the structural origin of the exceedingly high-performance MRI contrast of the GNTs, a more detailed extended X-ray absorption fine structure (EXAFS) study was performed [73], revealing essential information about the dynamic system around the clustered $\mathrm{Gd}^{3+}$ ions within the US-SWCNTs.

In another attempt to produce highly water-suspendable GNTs, following the encapsulation of the $\mathrm{Gd}^{3+}$ ions, the surface of the US-SWCNTs was functionalized with $p$ carboxyphenyldiazon ium (PCP) tetrafluoroborate salt, which covalently attached benzoic acid moieties, making the material highly water-suspendable $(35 \mathrm{mg} / \mathrm{mL})$ [74]. However, $90 \%$ of the $\mathrm{Gd}^{3+}$ ions leaked from the SWCNTs due to the acidic conditions of the functionalization process. To address this issue, US-SWCNTs, encapsulating the $\mathrm{Gd}(\mathrm{acac})_{3} \cdot 2 \mathrm{H}_{2} \mathrm{O}$ and $\mathrm{Gd}(\mathrm{hfac})_{3} \cdot 2 \mathrm{H}_{2} \mathrm{O}$ chelates were synthetized and the surface of the resulting material was functionalized with PCP, producing stable, highly water-suspendable US-SWCNTs containing $2.5-3.8 \%$ Gd by weight. These water-suspendable US-SWCNTs, encapsulating $\mathrm{Gd}(\mathrm{acac})_{3} \cdot 2 \mathrm{H}_{2} \mathrm{O}$, were then used to label porcine mesenchymal stem cells, making the cells MRI active without affecting cell viability [74].

Recently, the magnetic properties of metal impurities present in raw, commercially available CNTs (mainly from iron and nickel catalysts) have been studied for $T_{2}$-based contrast signal enhancement. A similar approach was employed to synthetize a Gd-based CA using $\mathrm{Gd}_{2} \mathrm{O}_{3}$ nanoparticles as catalysts to synthesize SWCNTs (Gd-SWCNTs) via chemical vapor deposition 
for $T_{1}$-weighted MRI [75-77]. The $\mathrm{Gd}^{3+}$ content of the final product was reported to be $6.2 \%$ and aqueous suspendability was achieved by non-covalent functionalization with a phospholipid polymer, PEG $_{5400}$-DSPE (PEG = polyethylene glycol, DSPE = 1,2-distearoyl-sn-glycero-3phosphoethanolamine) [77]. The cell-labeling efficacy was tested for NIH/3T3 fibroblast cells, which showed no change in viability, proliferation, or changes in their division cycle compared to untreated controls. Gd-SWCNTs localized to the cytoplasm and delivered $10^{8}-10^{9} \mathrm{Gd}^{3+}$ ions per cell. Phantom studies of the labeled cells using a $T_{1}$-weighted MRI at $3 \mathrm{~T}$ showed a four-fold increase in MR signal intensities compared to unlabeled cells. A continuation study [78] by the same group evaluated the in vivo pharmacodynamics of Gd-SWCNTs after intravenous (i.v.) injection $(0.5 \mathrm{mg} / \mathrm{kg})$ in male Wistar rats, which was assessed by bright-field optical microscopy. The macroscale distribution of the material showed uptake in the lungs, liver, kidneys, brain, and spleen. The histological distribution was also assessed and the molecular and genetic responses were evaluated for up to 30 days. After $24 \mathrm{~h}$, the Gd-SWCNT material accumulated in different organs leaving the circulatory system, with total elimination occurring in 10 days. However, in vivo MRI data for the Gd-SWCNTs were not obtained in any of the studies discussed above.

An alternative approach to synthetize CNT-based CAs containing $\mathrm{Gd}^{3+}$ is to use the CNT as a scaffold to covalently attach Gd-containing moieties to the surface of the material. A study performed by Marangon et al. reported the use of oxidized multi-walled carbon nanotubes (MWCNTs, 20-30 nm in diameter and $\sim 400 \mathrm{~nm}$ in length) functionalized with the chelating ligand diethylenetriaminepentaacetic dianhydride (DTPA), followed by metallation with $\mathrm{Gd}^{3+}$ (see Figure 4) [79]. RAW 264.7 mouse macrophage cells easily internalized the MWCNTs functionalized with Gd-DTPA, but showed little uptake of the free Gd-DTPA chelate itself. Cells labeled with increasing concentrations of the CNT-based material were dispersed in an agarose gel mimicking the cell density of tissue and MR images were acquired (Figure 5). For $\mathrm{T}_{1^{-}}$ weighted images, the signal increased nearly two fold for the highest concentration of the CA with respect to unlabeled cells. In vivo MRI studies were performed on female C57/B16 mice after i.v. administration of the material at two different doses $(2.5 \mathrm{mg} / \mathrm{kg}$ and $12.5 \mathrm{mg} / \mathrm{kg})$. At five hours following injection, MRI studies showed very large uptake of the Gd-based CA in the bladder, in addition to the liver and spleen. MRI, electron microscopy, and histological data suggested that a significant amount of the MWCNTs functionalized with Gd-DTPA is eliminated by renal clearance. 

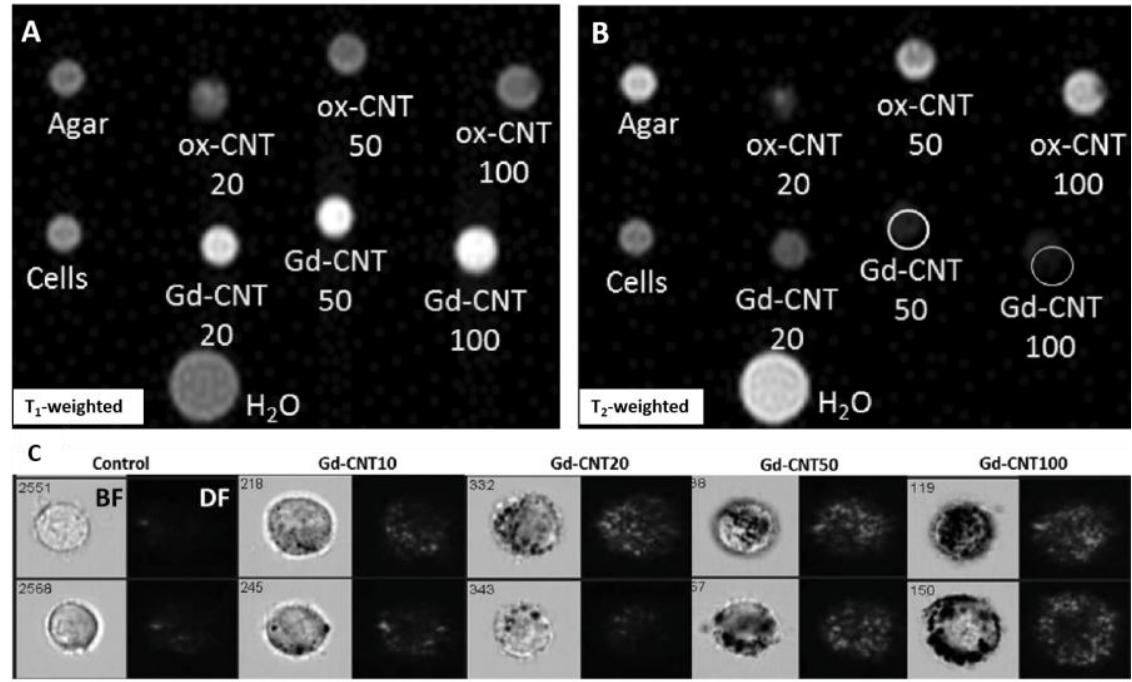

Figure 5: MR images of cells labeled with MWCNT functionalized with Gd-DTPA.

$T_{1}$-weighted (A) and $T_{2}$-weighted (B) fast spin echo MR images of compacted cells in agarose gel mimicking tissue $(70 \mu \mathrm{L})$ labeled with different concentrations $(10,20,50$ and $100 \mu \mathrm{g} / \mathrm{mL})$ of MWCNTs functionalized with Gd-DTPA or oxidized MWCNTs (ox-CNT). Images of agarose gel alone (agar), water, or unlabeled cells (cells) are also displayed. (C) Representative bright field and corresponding dark field images of cells for different concentrations of MWCNTs functionalized with Gd-DTPA. Black spots on bright field images and bright spots on dark field images are indicative of the material uptake. Adapted with permission from ref. [79], Copyright (2014) John Wiley and Sons. 


\subsection{Iron-based Contrast Agents}

As mentioned above, superparamagnetic iron oxide nanoparticles (SPIONs) have also been used as MRI CAs. The synthesis and general applications of CNTs filled with ferromagnetic materials have been under investigation for several years and previously reviewed [80]. More recently, Wu et al. reported the in situ loading of $\mathrm{Fe}_{3} \mathrm{O}_{4}$ nanoparticles on the surface of MWCNTs (10-30 $\mathrm{nm}$ in diameter, 0.5-2 $\mu \mathrm{m}$ in length) [81]. The $\mathrm{MWCNT} / \mathrm{Fe}_{3} \mathrm{O}_{4}$ hybrid material was synthetized by a solvothermal method using diethylene glycol and diethanolamine as solvents, producing a water-suspendable CA with superparamagnetic properties at room temperature and a $T_{2}$-relaxivity of $175.5 \mathrm{Fe} \mathrm{mM} \mathrm{m}^{-1}$. The amount of $\mathrm{Fe}_{3} \mathrm{O}_{4}$ in the MWCNT/ $\mathrm{Fe}_{3} \mathrm{O}_{4}$ hybrids was estimated to be $41.3 \%$. For in vitro studies, human breast adenocarcinoma cells (MCF-7) and mouse $\mathrm{C} 3 \mathrm{H} / \mathrm{An}$ connective tissue cells (L929) were incubated with $\mathrm{MWCNT} / \mathrm{Fe}_{3} \mathrm{O}_{4}$, maintaining cell viability greater than $80 \%$ after $24 \mathrm{~h}$ of treatment. In vivo MR images were acquired after i.v. administration of the $\mathrm{MWCNT} / \mathrm{Fe}_{3} \mathrm{O}_{4}$ into mice, showing uptake in the liver, lungs, and spleen.

A similar approach was performed by Al Faraj and coworkers [82,83]. A mixture of $\mathrm{H}_{2} \mathrm{SO}_{4}$ and $\mathrm{HNO}_{3}$ was used to oxidize SWCNTs, generating oxidized nanotubes, 200-300 nm in length, which were mixed with polyvinylpyrrolidone (PVP) polymer to obtain a stable suspension of the material in water. Iron chloride salts and ammonium hydroxide were employed to grow ferrous nanoparticle crystals on the SWCNTs. In these studies, the Fe-tagged SWCNT material was used as an MRI CA, as well as a magnetic agent to deliver drugs to tumors guided by an external magnetic field. Inductively-coupled plasma mass spectrometry (ICP-MS) revealed that the CNTs contained $40 \%(\mathrm{w} / \mathrm{w})$ iron oxide nanoparticles. This theranostic (therapeutic and diagnostic) agent was also conjugated with mouse Endoglin/CD105 monoclonal antibodies for specific active targeting of breast cancer tumors and with the anti-cancer drug, doxorubicin (DOX). A small magnet was placed over the tumor site to enable magnetic targeting. Tumor growth and progression were monitored using MRI, showing that DOX delivery through antibody-conjugated magnetic SWCNTs improved the efficacy (decreased tumor size) of DOX over control groups by improving targeting to the tumor site [82].

Another similar CNT-based MRI CA was reported by Liu et al., incorporating a lactoseglycine adduct around the SPION as a liver targeting functionality, while also preventing its oxidation [84]. MWCNTs were oxidized with a mixture of $\mathrm{H}_{2} \mathrm{SO}_{4}$ and $\mathrm{HNO}_{3}$, and further treated with citric acid to produce water-suspendable MWCNTs. Poly(diallydimethylammonium chloride) (PDDA) was coated on the surface of the acid-treated MWCNTs by electrostatic interactions and SPIONs, previously modified with the targeting agent by a co-precipitation 
method, were subsequently immobilized on the surface of the PDDA-MWCNTs. The hybrid material exhibited a $T_{2}$ relaxivity of $186 \mathrm{mM}^{-1} \mathrm{~s}^{-1}$ and was tracked in vivo by $T_{2}$-weighted MRI and found to accumulate in a murine orthotopic liver tumor model following i.v. injection $(10 \mathrm{mg} / \mathrm{kg})$ with low observed toxicity. Subsequently, the same group reported SPIONs within the inner cavity of MWCNTs, ensuring high mechanical stability of the nanoparticles [85], although with lower relaxivity values than the previously reported material $\left(R_{2}=85 \mathrm{mM}^{-1} \mathrm{~s}^{-1}\right)$. The synthesis was achieved by mixing the same acid-treated MWCNTs (20-50 nm inner diameter) with $\mathrm{Fe}(\mathrm{acac})_{3}$, followed by its reduction to $\mathrm{Fe}_{3} \mathrm{O}_{4}$ with $\mathrm{N}_{2} \mathrm{H}_{4}$ using a microwave reactor. Finally, the nanostructure was coated with diblock copolymers PMETAC- $b$-PEGMA, (PMETAC: 2(Methacryloxy)ethyl trimethylammonium chloride, PEGMA: Poly(ethylene glycol) methacrylate) to achieve high suspendability in water. Diblock copolymers were prepared with different PEGMA block lengths (degree of polymerization $=20,60,89$, and 118 , named $\mathrm{P}_{1}-\mathrm{P}_{4}$, respectively) and the same PMETAC block length (degree of polymerization $=10$ ). In vitro studies performed with two cancer cell lines demonstrated low cytotoxicity using up to 200 $\mu \mathrm{g} / \mathrm{mL}$, and $T_{2}$-weighted MR images of a cancerous mouse liver showed an increased tumor/liver contrast ratio after administration of the material (Figure 6).

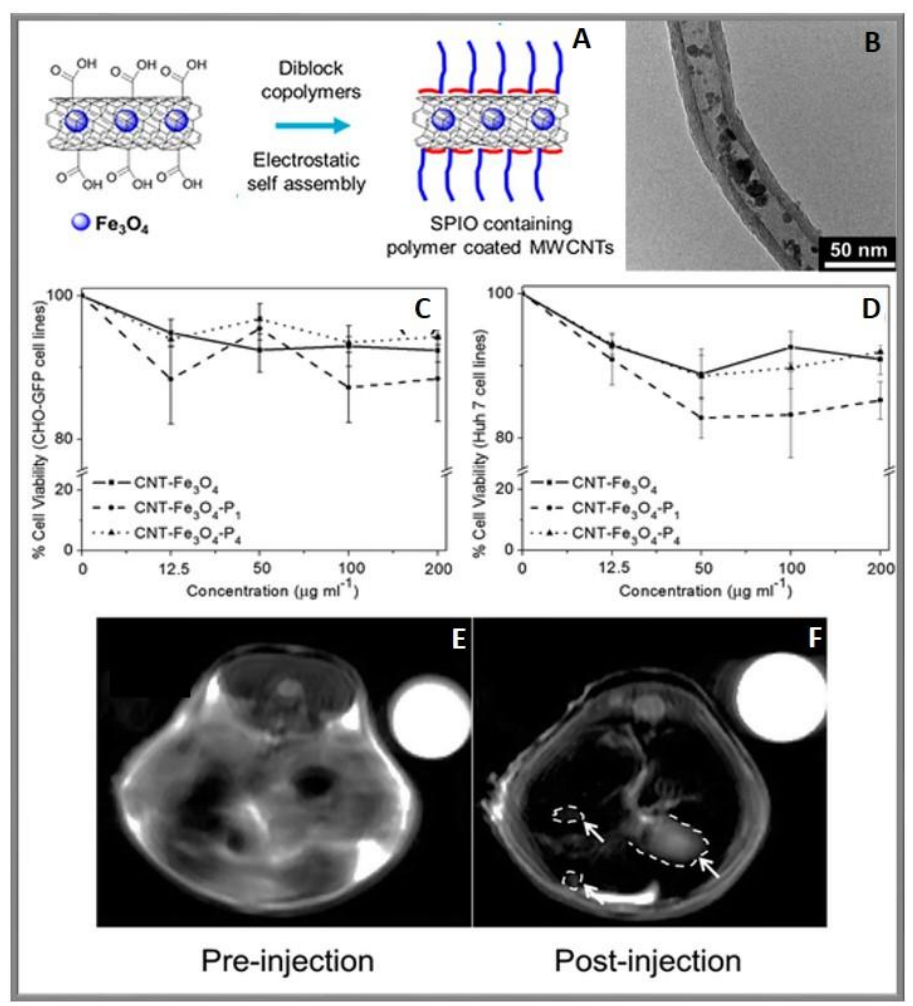

Figure 6: Properties and imaging of $\mathbf{C N T}-\mathrm{Fe}_{3} \mathrm{O}_{4}$. (A) Last step of the CNT- $\mathrm{Fe}_{3} \mathrm{O}_{4}$ polymer preparation. (B) TEM images of CNT- $\mathrm{Fe}_{3} \mathrm{O}_{4}-\mathrm{P}_{4}$. Cytotoxicity results of CHO-GFP (C) and Huh7 (D) cell lines labeled with the CNT- $\mathrm{Fe}_{3} \mathrm{O}_{4}$ derivatives $\left(\mathrm{CNT}-\mathrm{Fe}_{3} \mathrm{O}_{4}, \mathrm{CNT}-\mathrm{Fe}_{3} \mathrm{O}_{4}-\mathrm{P}_{1}\right.$, and CNT- $\left.\mathrm{Fe}_{3} \mathrm{O}_{4}-\mathrm{P}_{4}\right)$. (E)(F) In vivo $\mathrm{MR}$ 
images of mouse liver pre- and post-injection of CNT- $\mathrm{Fe}_{3} \mathrm{O}_{4}-\mathrm{P}_{4}$ at a dose of $100 \mathrm{mg} / \mathrm{kg}$, with white arrows indicating tumors. Adapted with permission from ref. [85], Copyright (2015) American Chemical Society.

Another theranostic agent consisting of a ferromagnetic material encapsulated inside MWCNTs has been reported by Peci et al., however in this case, the magnetic material was in the form of a wire [86]. The iron nanowire, termed iron-filled MWCNTs (Fe-MWCNTs), displayed high coercivity due to shape anisotropy, promoting its use in cancer therapy as a magnetic hyperthermia agent. In this case, the authors added $\mathrm{Gd}^{3+}$ ions to the surface of the Fe-MWCNTs by sonication with $\mathrm{GdCl}_{3}$, which resulted in attachment of $\mathrm{Gd}^{3+}$ ions on the MWCNT sidewalls. This resulted in a dual-function agent owing to the integration of both the heating element (the $\mathrm{Fe}$ nanowire) and the paramagnetic $\mathrm{Gd}^{3+}$ ions that generated MRI contrast. Although the structures were well characterized, no MR images were reported and the biological stability of the $\mathrm{Gd}^{3+}$ ions was not evaluated.

A $T_{2}$-weighted MRI signal is also observed from CNTs containing metal impurities such as iron and nickel. Such a phenomenon was exploited to study the chronic toxic effect of raw SWCNTs to the lungs through a long-term (3 months) follow-up study that was achieved by hyperpolarized helium-3 ( $\mathrm{HP}-{ }^{3} \mathrm{He}$ ) MRI [87], a technique that is used for clinical pulmonary research and has been described previously [88]. Intratracheal instillation of SWCNTs was performed in rats and the amount of metal impurities in the CNTs were large enough to produce a significant drop in magnetic field homogeneity as detected in the ${ }^{3} \mathrm{He}$ MR images. In another study, MRI in conjunction with Raman spectroscopy and iron bio-assays, was used to assess the biodistribution of intravenously injected pristine (raw and purified) and functionalized SWCNTs in a two-week study [89]. The intrinsic iron impurities (11\% by weight) in the raw sample allowed the in vivo detection of SWCNTs by MRI. In a similar report, commercial HiPCO SWCNTs were non-covalently coated with amine-terminated PEG and relaxivity values, as well as two-dimensional images of solid phantoms were acquired [90]. The trace amount of iron in the sample was sufficient to distinguish a difference from the background in the MRI scan at nanomolar concentrations.

The potential of MWCNTs with low metal impurities $(2.57 \% \mathrm{Fe}$ by weight) as intracellular MRI CAs was exploited by Vittorio and coworkers [91]. A solution of $0.1 \%$ Pluronic ${ }^{\circledR}$ F127 in phosphate-buffered saline (PBS) was used to make an aqueous suspension of the MWCNTs and mesenchymal stem cells from the bone marrow of rats were used for in vitro studies. MR images of the CNT suspension and of labeled cells at different CNT concentrations showed that the low Fe content in the CNTs was sufficient to visualize the cells by $T_{2}$-weighted MRI. As shown above, MRI provides a very efficient method for tracking CNTs as well as 
tracking cells using CNT-based intracellular probes since MR images elucidate anatomical structures with very high resolution. However, MRI is limited by its low sensitivity, which requires large concentrations (e.g. $1 \mathrm{mM}$ ) in order to produce high quality images when using a CA.

\section{CNT-based Agents for Nuclear Imaging}

Among the nuclear imaging techniques, SPECT and PET have become important tools in both clinical and research settings. The way a SPECT image is generated is by having one or two detectors rotate to identify gamma $(\gamma)$ rays emitted from a decaying radionuclide inside the patient and convert the detected energy into an electrical signal, which is then processed into an image. In PET imaging, radionuclei release positrons $\left(\beta^{+}\right)$, which interact with electrons in their vicinity and annihilate one another, emitting two $\gamma$ rays $180^{\circ}$ with respect to each other with identical energies of $511 \mathrm{keV}$. The $\gamma$ rays are detected by a ring of detectors that register coincident rays coming from a single event along a given line of response. In both types of imaging, two-dimensional cross-sections of the subject from multiple angles can be reconstructed and stacked to create a three-dimensional image [92]. When compared to MR and X-ray imaging techniques, which offer structural information with very high resolution, nuclear imaging techniques offer functional information and the ability to quantitatively track material in vivo with very high sensitivity. PET is a far more sensitive technique than SPECT, requiring material concentrations of only $10^{-10}$ to $10^{-12} \mathrm{M}$, whereas SPECT requires concentrations of about $10^{-6} \mathrm{M}$. Furthermore, PET often has higher resolution (2-3 mm) than SPECT $(6-8 \mathrm{~mm})$ [93,94].

\subsection{CNT-based Agents for SPECT}

Hong et al. filled short SWCNTs (approximately $300 \mathrm{~nm}$ in length) with $\mathrm{Na}^{125} \mathrm{I}_{\left(\mathrm{t}_{1 / 2}\right.}=59$ d) and determined tissue localization using SPECT [95]. In this report, the authors first employed a steam purification technique to shorten the SWCNTs and remove any graphitic and metal impurities. SWCNTs were subsequently loaded with $\mathrm{Na}^{125} \mathrm{I}$ by molten-phase capillary wetting and covalently surface-functionalized with $N$-acetylglucosamine sugar molecules. The material was then characterized using TEM and scanning transmission electron microscopy (STEM). The radiolabeled, functionalized SWCNTs were injected i.v. in mice and imaged using SPECT, showing localization predominately in the lungs with about $80 \%$ injected dose per gram of tissue (\% ID/g) up to $24 \mathrm{~h}$, and a negligible amount was found in the blood $3 \mathrm{~min}$ after injection. Histological analysis of lungs, liver, spleen, and kidneys corroborated the SPECT imaging data and showed no sign of tissue necrosis or other acute (24 h) or long-term (30 d) abnormalities. 
Another study by Al-Jamal et al. used SPECT imaging of MWCNTs radiolabeled with ${ }^{111}$ In $\left(\mathrm{t}_{1 / 2}=67.5 \mathrm{~h}\right)$ to determine effects of specific chemical functionalization on the distribution and excretion of the MWCNTs [96]. The authors investigated three different samples: MWCNTs 6, 7, and 8. The first sample, MWCNT 6, was functionalized solely by 1,3-dipolar cycloaddition [97] and then conjugated to DTPA. The other two samples, MWCNTs 7 and 8, were first oxidized, shortening and introducing carboxylate groups to the surface of the nanotubes, followed by amidation with diaminotriethyleneglycol, introducing amino groups to the surface of the nanotubes, and then finally conjugating DTPA to the material using amide coupling. MWCNT 8 was functionalized for a second time after learning that the MWCNT 7 sample had extra free amino groups on the surface after coupling to DTPA and therefore had approximately twice the amount of functionalization as MWCNTs 6 and 7. TEM indicated that the mean diameter of the MWCNTs was $34.1 \pm 10.2 \mathrm{~nm}$ with lengths of $773 \pm 425 \mathrm{~nm}$ for the precursors of MWCNT 6 and $354 \pm 170 \mathrm{~nm}$ for the precursors of MWCNTs $\mathbf{7}$ and $\mathbf{8}$. The study reported that the sample with the highest degree of functionalization (MWCNT 8) accumulated in the spleen and lungs. Meanwhile, MWCNT 8 showed reduced liver accumulation and greater renal excretion in contrast with the other samples, which aggregated and remained in the liver, spleen, and lungs (see Figure 7). The authors of this study and others have also previously reported $[98,99]$ that only individualized (non-bundled) CNTs with average diameters of 20-30 nm can be excreted through the kidneys.

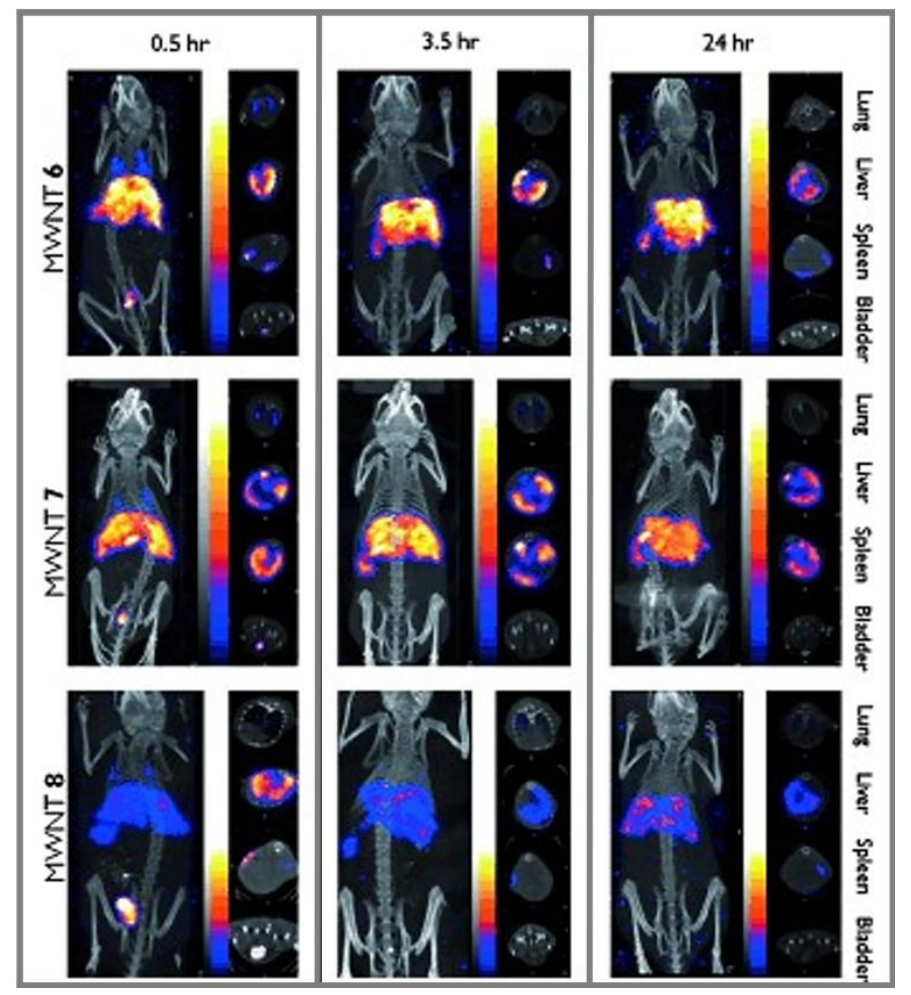


Figure 7: SPECT/CT fused images of the whole mouse post-administration of ${ }^{111}$ In-DTPA-MWCNTs. Images were taken at 0.5, 3.5 and $24 \mathrm{~h}$ post-injection for MWCNTs 6, 7, and 8 after injection of $50 \mu \mathrm{g}$ of ${ }^{111} \mathrm{In}$-DTPA-MWCNTs with a scanning time up to $0.5 \mathrm{~h}$. Reproduced with permission from ref. [96], Copyright (2012) John Wiley and Sons.

\subsection{CNT-based Agents for PET}

McDevitt and coworkers developed an amine-functionalized SWCNT material that was conjugated to both the tumor neovascular-targeting antibody E4G10 and to one of two different metal chelates that contained either ${ }^{225} \mathrm{Ac}^{3+}$, an alpha emitter for radiotherapy $\left(t_{1 / 2}=10 \mathrm{~d}\right)$ chelated by 1,4,7,10-tetraazacyclododecane-1,4,7,10-tetraacetic acid (DOTA), or ${ }^{89} \mathrm{Zr}^{4+}$, a $\beta^{+}$emitter for PET imaging $\left(\mathrm{t}_{1 / 2}=78 \mathrm{~h}\right)$ chelated by desferrioxamine B [100]. Using the targeted, radiolabeled SWCNT material resulted in an approximately five-fold increase in specific activity, which improved the signal-to-noise ratio of the image. Another study by Huang et al. examined the effects on fetotoxicity of water-suspendable SWCNTs and MWCNTs and used PET to study material localization in pregnant mice and their fetuses [101]. The CNTs were non-covalently functionalized using an amino-phospholipid-poly(ethylene glycol) (PL-PEG- $\mathrm{NH}_{2}$ ) derivative as previously reported [102] with DOTA then conjugated to the CNTs in order to radiolabel the material with ${ }^{64} \mathrm{Cu}^{2+}\left(\mathrm{t}_{1 / 2}=12.7 \mathrm{~h}\right)$. The samples tested were short SWCNTs and MWCNTs of similar lengths $(0.5-2 \mu \mathrm{m})$, with various outer diameters of MWCNTs: < $8 \mathrm{~nm}$ (MWCNT-8), 20$30 \mathrm{~nm}$ (MWCNT-20), and $~ 50 \mathrm{~nm}$ (MWCNT-50). Toxicity results indicated that MWCNT-50 had a more toxic effect on fetuses than the SWCNT, MWCNT-8, and MWCNT-20 samples at the same dose. MWCNT-50 also was shown to decrease the long-term survival of the offspring, with a $>20 \%$ lethality rate. PET imaging results showed that the material accumulated in the liver with high uptake values (10-12\% $\mathrm{ID} / \mathrm{g})$, as well as in the uterus of pregnant mice at $48 \mathrm{~h}$ post-injection. The fetuses were then harvested and imaged at $48 \mathrm{~h}$ post-injection and showed CNT uptake in the fetal liver and placenta. The authors concluded that functionalized MWCNTs (particularly MWCNT-50) more readily induced toxicity in mouse fetuses than other derivatives at similar doses. Since the biodistribution and the uptake values of the CNTs were similar, the study concluded that any toxicity that was observed must not be from the amount of uptake, but from other properties of the CNTs, such as the diameter, agglomeration state, etc. These and other studies have concluded that among all the nuclear medicine techniques, SPECT and PET can be used to effectively track minute amounts of material in vivo due to their high sensitivity. 


\section{CNT-based Agents for X-ray CT}

Despite the introduction and growth of MR, ultrasound, and nuclear imaging systems, Xray remains one of the main imaging modalities today due to its cost-effectiveness and diverse applicability. X-ray CT combines multiple X-ray projections taken from different angles to produce detailed cross-sectional images of the body. Contrast enhancement comes largely from the photoelectron effect due to high atomic numbers, thus hard tissue such as bone and cartilage have high attenuation compared to soft tissues due to the high concentration of calcium. Currently, there are two types of approved X-ray CAs for human use: barium sulfate suspensions (strictly used for imaging the gastrointestinal tract) and iodinated molecules. There are many elements with larger atomic numbers than iodine, thus the current use of iodinated CAs is mostly based on their superior safety and cost rather than their optimal efficacy as X-ray attenuators [103]. Some metals, metal salts, and metal particulates have been shown to be excellent X-ray CAs, such as bismuth sulfide [104,105] and gold nanoparticles [106,107].

Little research involving CNT-based CAs for X-ray has been developed, mostly due to the high CA concentration needed to produce good contrast and the poor water solubility and dispersion achieved with CNTs in aqueous media. Previously, functionalized US-SWCNTs (20$80 \mathrm{~nm}$ ) filled with $\mathrm{I}_{2}$ were synthetized and the X-ray attenuation was tested, although no in vitro or in vivo studies were performed [108]. More recently, $\mathrm{Bi}^{3+}$ ions and $\mathrm{Bi}_{2} \mathrm{O}_{3}$ were encapsulated in US-SWCNTs using $\mathrm{BiCl}_{3}$ as the bismuth source, followed by suspension of the material in a $0.17 \%$ Pluronic $^{\circledR}$ solution. Bismuth was chosen as a substitute for iodide due to its higher atomic number and lower toxicity $[109,110]$. In vitro studies were performed in porcine mesenchymal stem cells, causing no observed cytotoxicity to the cells while increasing the X-ray attenuation when compared with control cells [111]. With today's technology, single-cell tracking using CT is not promising [112], however, 3D structures of cells such as stem cell-engineered cell sheets, cells encapsulated in hydrogels or capsules, among others, can be monitored with CT [113-115]. In general, CT still is one of the most used clinical modalities and more efforts regarding the development of new CAs should be considered in order to limit the radiation dose to the patient.

\section{CNT-based Agents for Multimodal Imaging}

Currently, nuclear images are often overlaid with a CT image to generate a composite image, which provides anatomical information for image analysis. However, due to the much higher resolution of MRI over CT, there is an increasing interest in combining the ultra-high resolution of MRI with the high sensitivity of SPECT and PET in a single image. Recently, there have been many reports of creating multimodal imaging agents for new multimodal 
Figure 8: Bimodal imaging of MRI/PET CNT agents. (A, C, E) Micro-PET/CT images of normal mice injected with surfactant-wrapped US-SWCNTs filled with ${ }^{64} \mathrm{Cu}^{2+}$ and $\mathrm{Gd}^{3+}$ (referred to as ${ }^{64} \mathrm{Cu} @ \mathrm{GNT}$ ) or free ${ }^{64} \mathrm{Cu}^{2+}$. (B, D, F) Histograms show quantification of the material at 4, 24, and $48 \mathrm{~h}$ postinjection. (A.a.) The arrows highlight the presence of ${ }^{64} \mathrm{Cu}^{2+}$ in the liver (white arrow) and gastrointestinal tract (yellow arrow) for free ${ }^{64} \mathrm{Cu}^{2+}$, (A.b.) and in the lungs (red arrow). Error bars represent mean \pm SD. ${ }^{*} \mathrm{p} \leq 0.05$; ${ }^{*}$ p $\leq 0.01$. Adapted with permission from ref. [118], Copyright (2014) Future Medicine Ltd. 
Wang et al. also developed a bimodal imaging agent based on MWCNTs that were conjugated to SPIONs for MRI contrast and then radiolabeled with ${ }^{99 \mathrm{~m}} \mathrm{Tc}\left(\mathrm{t}_{1 / 2}=6 \mathrm{~h}\right)$ for SPECT imaging [119]. Functionalized MWCNTs were mixed with iron acetate, which served as the precursor to the SPIONs that grew along the backbone of the MWCNTs with different amounts of SPIONs loaded on the MWCNTs, henceforth referred to as S-MWCNTs (superparamagnetic MWCNTs). The two main samples that were studied were S-MWCNT-2 (28.0\% SPION by weight) and S-MWCNT-3 (41.5\% SPION by weight). Relaxation measurements that were performed on the S-MWCNTs 2 and 3 showed $\mathrm{r}_{2}$ * relaxivities of $343 \mathrm{mM}^{-1} \mathrm{~s}^{-1}$ and $425 \mathrm{mM}^{-1} \mathrm{~s}^{-1}$, respectively. The SPION-MWCNT conjugates were then radiolabeled with ${ }^{99 \mathrm{~m}} \mathrm{Tc}$ with good efficiency by using dipicolylamine-alendronate as a linker between the radionuclide and the SPIONs, although S-MWCNT-3 showed the best radiolabeling yields and biological stability and was exclusively used in subsequent imaging studies. Tissue distribution from whole-body SPECT/CT imaging showed prevalent accumulation in the lungs, liver, and spleen within $30 \mathrm{~min}$ of i.v. injection. After $4 \mathrm{~h}$ post-injection, while the liver signals remained constant, there was a clear decrease in lung uptake and SPECT results were verified with post-mortem gammascintigraphy. In vivo MR images were also obtained of the liver using S-MWCNT-3, which showed good relaxation rates that increased linearly with increasing dose of material. In vitro studies of S-MWCNT-3 using a mouse macrophage cell line with concentrations up to 100 $\mu \mathrm{g} / \mathrm{mL}$ after $24 \mathrm{~h}$ incubation found no significant cytotoxicity in addition to any histological abnormalities in mouse tissues up to 30 days.

Similarly, Al Faraj and coworkers recently developed a multifunctional SWCNT agent conjugating SPIONs and gallium-67 ( $\mathrm{t}_{1 / 2}=3.26$ days) for MRI and SPECT, respectively, in order to target and image breast cancer stem cells [120]. SWCNTs were oxidized and shortened to about $200 \mathrm{~nm}$ in length. The oxidized CNTs were then PEGylated and conjugated to SPIONs and DOTA to chelate gallium-67 for imaging, in addition to CD44 monoclonal antibodies for cancer stem cell targeting. SPECT imaging studies in mice showed significant material accumulation in reticuloendothelial organs (liver and spleen) as well as the kidneys and heart, but to a lesser extent. Tumor homing was enhanced after injection of the antibody-conjugated samples compared to untargeted controls. SPECT data were confirmed using MRI and post-mortem gallium-67 quantification using a gamma counter. Since the amount of material accumulation at 2, 24, and $48 \mathrm{~h}$ time points was statistically similar, the authors suggested that the material was cleared slowly from the mouse. The authors also substituted the gallium-67 for a near-infrared fluorescence probe and conducted imaging studies, which yielded very similar results as the SPECT and MRI studies. With the development of multimodal imaging instrumentation, it is 
expected that this field will grow and more multipurpose agents, both for imaging and therapeutic applications will begin to appear in the literature.

\section{Conclusion}

This review documents many examples of CNT materials, which have been labeled with one or more imaging agents, and functionalized for water suspendability to image non-invasively. While other CNT-based CAs have been synthesized for other imaging techniques, we have chosen to focus on those full-body imaging modalities most used in the clinic today (MRI, X-ray CT, SPECT, and PET), and therefore exhibit the most translational potential. The examples presented here have shown that appropriately functionalized CNT materials are a versatile platform with potential for a wide-range of imaging and therapeutic applications in medicine. In general, the studies reviewed have also shown that properly purified and derivatized CNT materials are non-toxic at reasonable clinical concentrations. While this is true for the nuclear imaging techniques of SPECT and PET, this is less certain for MR and X-ray CT imaging where concentrations in the millimolar range are required. In fact, new functionalization procedures aimed at increasing CNT agent suspendability into the millimolar range or above are still needed for toxicity and performance testing at these levels. For a complete discussion on the toxicity of CNTs, the authors direct the readers to the following review articles [121-123].

Some of the currently accepted criteria for clinical imaging agents are that the agent should (1) be safe (non-toxic), (2) have sufficiently high performance for the imaging techniques needed and (3) be stable in vivo long enough to perform the imaging function until eventual elimination or biodegradation. In fact, recent research has focused on peroxidase-driven biodegradation of CNTs, and other natural enzymatic catalysis [124-126]. Finally and most importantly, the agent must be reproducibility produced using good manufacturing practices as required by the U.S. Food and Drug Administration. This requirement implies that SWCNTs should be superior to MWCNTs for CNT-based agent design simply because MWCNTs are a far less uniform material.

While several CNT-based materials in the literature have already satisfied most of the above criteria, two major problems linger. Namely, more work is needed to create a more uniform particle distribution in both size (length) and degree of functionalization. Secondly, more preclinical data is needed which quantifies and potentially proves total elimination of the CNT agents from the body over time. Finally, CNT-based materials have been shown to surpass the performance of all other nanoparticle and small molecule CAs, while maintaining high biocompatibility. For example, the "Gadonanotubes" provide unrivaled performance as MRI CAs 
with relaxivities up to 40 times greater (on a per $\mathrm{Gd}^{3+}$-ion basis) than current $\mathrm{Gd}^{3+}$-based CAs in the clinic [63]. Studies have shown that this phenomenon is due to the encapsulation of $\mathrm{Gd}^{3+}$-ion clusters within the cavities of the US-SWCNTs and the special $\mathrm{Gd}^{3+}$ ion-water interaction for that specific environment. Such findings provide us with valuable information about the physics behind the performance of the agents and about the contrast enhancement phenomenon, which allow us to possibly design more powerful CAs. This is just one of the many surprises that other new CNT-based CA might also provide. Therefore, the search for new CNT-based CAs should go on to explore the possibilities, while parallel efforts are also needed to seek pathways toward clinical approval for key CNT-based CAs that emerge from such studies.

\section{Acknowledgements}

This work was supported by the Welch Foundation (Grant C-0627; L. J. Wilson) and the National Science Foundation Graduate Research Fellowship Program 1450681 (N. G. Zaibaq).

\section{References}

1. Odom TW, Huang J-L, Kim P, Lieber CM. Atomic structure and electronic properties of single-walled carbon nanotubes. Nature 1998;391:62-4.

2. Wilder JWG, Venema LC, Rinzler AG, Smalley RE, Dekker C. Electronic structure of atomically resolved carbon nanotubes. Nature 1998;391:59-62.

3. Liu C, Cong HT, Li F, Tan PH, Cheng HM, Lu K, et al. Semi-continuous synthesis of single-walled carbon nanotubes by a hydrogen arc discharge method. Carbon 1999;37:1865-8.

4. Hutchison JL, Kiselev NA, Krinichnaya EP, Krestinin AV, Loutfy RO, Morawsky AP, et al. Double-walled carbon nanotubes fabricated by a hydrogen arc discharge method. Carbon 2001;39:761-70.

5. Bethune DS, Klang CH, de Vries MS, Gorman G, Savoy R, Vazquez J, et al. Cobalt-catalysed growth of carbon nanotubes with single-atomic-layer walls. Nature 1993;363:605-7.

6. Meyyappan M, Delzeit L, Cassell A, Hash D. Carbon nanotube growth by PECVD: a review. Plasma Sources Sci. Technol. 2003;12:205.

7. Dupuis A-C. The catalyst in the CCVD of carbon nanotubes-a review. Prog. Mater. Sci. 2005;50:929-61.

8. Moisala A, Nasibulin AG, Kauppinen EI. The role of metal nanoparticles in the catalytic production of single-walled carbon nanotubes - a review. J. Phys. Condens. Matter 2003;15:S3011. 
9. Hernadi K, Fonseca A, Nagy JB, Bernaerts D, Riga J, Lucas A. Catalytic synthesis and purification of carbon nanotubes. Synth. Met. 1996;77:31-4.

10. Colomer J-F, Piedigrosso P, Fonseca A, Nagy JB. Different purification methods of carbon nanotubes produced by catalytic synthesis. Synth. Met. 1999;103:2482-3.

11. Hou PX, Bai S, Yang QH, Liu C, Cheng HM. Multi-step purification of carbon nanotubes. Carbon 2002;40:81-5.

12. Mackeyev Y, Bachilo S, Hartman KB, Wilson LJ. The purification of HiPco SWCNTs with liquid bromine at room temperature. Carbon 2007;45:1013-7.

13. Chiang IW, Brinson BE, Huang AY, Willis PA, Bronikowski MJ, Margrave JL, et al. Purification and characterization of single-wall carbon nanotubes (SWNTs) obtained from the gas-phase decomposition of co (HiPco process). J. Phys. Chem. B 2001;105:8297-301.

14. Iijima S. Helical microtubules of graphitic carbon. Nature 1991;354:56-8.

15. Yu M-F, Lourie O, Dyer MJ, Moloni K, Kelly TF, Ruoff RS. Strength and breaking mechanism of multiwalled carbon nanotubes under tensile load. Science 2000;287:637-40.

16. Volder MFLD, Tawfick SH, Baughman RH, Hart AJ. Carbon nanotubes: present and future commercial applications. Science 2013;339:535-9.

17. Baughman RH, Zakhidov AA, Heer WA de. Carbon nanotubes-the route toward applications. Science 2002;297:787-92.

18. Popov VN. Carbon nanotubes: properties and application. Mater. Sci. Eng. R Rep. 2004;43:61-102.

19. Ouyang M, Huang J-L, Lieber CM. Fundamental electronic properties and applications of single-walled carbon nanotubes. Acc. Chem. Res. 2002;35:1018-25.

20. Futaba DN, Hata K, Yamada T, Hiraoka T, Hayamizu Y, Kakudate Y, et al. Shapeengineerable and highly densely packed single-walled carbon nanotubes and their application as super-capacitor electrodes. Nat. Mater. 2006;5:987-94.

21. Baibarac M, Gómez-Romero P. Nanocomposites based on conducting polymers and carbon nanotubes: from fancy materials to functional applications. J. Nanosci. Nanotechnol. 2006;6:289-302.

22. Liu C, Cheng H-M. Carbon nanotubes for clean energy applications. J. Phys. Appl. Phys. 2005;38:R231. 
23. Planeix JM, Coustel N, Coq B, Brotons V, Kumbhar PS, Dutartre R, et al. Application of carbon nanotubes as supports in heterogeneous catalysis. J. Am. Chem. Soc. 1994;116:7935-6.

24. Che G, Lakshmi BB, Martin CR, Fisher ER. Metal-nanocluster-nilled carbon nanotubes: catalytic properties and possible applications in electrochemical energy storage and production. Langmuir 1999;15:750-8.

25. Sinha N, Yeow JTW. Carbon nanotubes for biomedical applications. IEEE Trans. Nanobioscience 2005;4:180-95.

26. He H, Pham-Huy LA, Dramou P, Xiao D, Zuo P, Pham-Huy C, et al. Carbon nanotubes: applications in pharmacy and medicine. BioMed Res. Int. BioMed Res. Int. 2013;2013:e578290.

27. Wu H-C, Chang X, Liu L, Zhao F, Zhao Y. Chemistry of carbon nanotubes in biomedical applications. J. Mater. Chem. 2010;20:1036-52.

28. Guven A, Rusakova IA, Lewis MT, Wilson LJ. Cisplatin@US-tube carbon nanocapsules for enhanced chemotherapeutic delivery. Biomaterials 2012;33:145561 .

29. Raoof M, Cisneros BT, Guven A, Phounsavath S, Corr SJ, Wilson LJ, et al. Remotely triggered cisplatin release from carbon nanocapsules by radiofrequency fields. Biomaterials 2013;34:1862-9.

30. Mashal A, Sitharaman B, Li X, Avti PK, Sahakian AV, Booske JH, et al. Toward carbon-nanotube-based theranostic agents for microwave detection and treatment of breast cancer: enhanced dielectric and heating response of tissue-mimicking materials. IEEE Trans. Biomed. Eng. 2010;57:1831-4.

31. Chou H-T, Wang T-P, Lee C-Y, Tai N-H, Chang H-Y. Photothermal effects of multi-walled carbon nanotubes on the viability of BT-474 cancer cells. Mater. Sci. Eng. C 2013;33:989-95.

32. Gannon CJ, Cherukuri P, Yakobson BI, Cognet L, Kanzius JS, Kittrell C, et al. Carbon nanotube-enhanced thermal destruction of cancer cells in a noninvasive radiofrequency field. Cancer 2007;110:2654-65.

33. Corr SJ, Raoof M, Cisneros BT, Orbaek AW, Cheney MA, Law JJ, et al. Radiofrequency electric-field heating behaviors of highly enriched semiconducting and metallic single-walled carbon nanotubes. Nano Res. 2015;8:2859-70.

34. Shin SR, Jung SM, Zalabany M, Kim K, Zorlutuna P, Kim S bok, et al. Carbonnanotube-embedded hydrogel sheets for engineering cardiac constructs and bioactuators. ACS Nano 2013;7:2369-80. 
35. Liu Z, Yang K, Lee S-T. Single-walled carbon nanotubes in biomedical imaging. J. Mater. Chem. 2010;21:586-98.

36. Hong G, Diao S, Antaris AL, Dai H. Carbon nanomaterials for biological imaging and nanomedicinal therapy. Chem. Rev. 2015;115:10816-906.

37. Kang JW, Nguyen FT, Lue N, Dasari RR, Heller DA. Measuring uptake dynamics of multiple identifiable carbon nanotube species via high-speed confocal raman imaging of live cells. Nano Lett. 2012;12:6170-4.

38. Lefebvre J, Austing DG, Bond J, Finnie P. Photoluminescence imaging of suspended single-walled carbon nanotubes. Nano Lett. 2006;6:1603-8.

39. Welsher K, Liu Z, Daranciang D, Dai H. Selective probing and imaging of cells with single walled carbon nanotubes as near-infrared fluorescent molecules. Nano Lett. 2008;8:586-90.

40. O’Connell MJ, Bachilo SM, Huffman CB, Moore VC, Strano MS, Haroz EH, et al. Band gap fluorescence from individual single-walled carbon nanotubes. Science 2002;297:593-6.

41. De La Zerda A, Zavaleta C, Keren S, Vaithilingam S, Bodapati S, Liu Z, et al. Carbon nanotubes as photoacoustic molecular imaging agents in living mice. Nat. Nanotechnol. 2008;3:557-62.

42. Pramanik M, Swierczewska M, Green D, Sitharaman B, Wang LV. Single-walled carbon nanotubes as a multimodal-thermoacoustic and photoacoustic-contrast agent. J. Biomed. Opt. 2009;14:034018-034018 - 8.

43. Kim J-W, Galanzha EI, Shashkov EV, Moon H-M, Zharov VP. Golden carbon nanotubes as multimodal photoacoustic and photothermal high-contrast molecular agents. Nat. Nanotechnol. 2009;4:688-94.

44. Wang C, Ma X, Ye S, Cheng L, Yang K, Guo L, et al. Protamine functionalized single-walled carbon nanotubes for stem cell labeling and in vivo raman/magnetic resonance/photoacoustic triple-modal imaging. Adv. Funct. Mater. 2012;22:236375.

45. Pramanik M, Swierczewska M, Green D, Sitharaman B, Wang LV. Single-walled carbon nanotubes as a multimodal-thermoacoustic and photoacoustic-contrast agent. J. Biomed. Opt. 2009;14:034018-034018-8.

46. Delogu LG, Vidili G, Venturelli E, Ménard-Moyon C, Zoroddu MA, Pilo G, et al. Functionalized multiwalled carbon nanotubes as ultrasound contrast agents. Proc. Natl. Acad. Sci. U. S. A. 2012;109:16612-7.

47. Kherlopian AR, Song T, Duan Q, Neimark MA, Po MJ, Gohagan JK, et al. A review of imaging techniques for systems biology. BMC Syst. Biol. 2008;2:74. 
48. Ke H, Erpelding TN, Jankovic L, Liu C, Wang LV. Performance characterization of an integrated ultrasound, photoacoustic, and thermoacoustic imaging system. J. Biomed. Opt. 2012;15;5

49. Yaron PN, Holt BD, Short PA, Lösche M, Islam MF, Dahl K. Single wall carbon nanotubes enter cells by endocytosis and not membrane penetration. J. Nanobiotechnology 2011;9:45.

50. Kostura L, Kraitchman DL, Mackay AM, Pittenger MF, Bulte JWM. Feridex labeling of mesenchymal stem cells inhibits chondrogenesis but not adipogenesis or osteogenesis. NMR Biomed. 2004;17:513-7.

51. Arbab AS, Yocum GT, Wilson LB, Parwana A, Jordan EK, Kalish H, et al. Comparison of transfection agents in forming complexes with ferumoxides, cell labeling efficiency, and cellular viability. Mol. Imaging 2004;3:24-32.

52. Georgakilas V, Kordatos K, Prato M, Guldi DM, Holzinger M, Hirsch A. Organic functionalization of carbon naanotubes. J. Am. Chem. Soc. 2002;124:760-1.

53. Singh P, Campidelli S, Giordani S, Bonifazi D, Bianco A, Prato M. Organic functionalisation and characterisation of single-walled carbon nanotubes. Chem. Soc. Rev. 2009;38:2214-30.

54. Banerjee S, Hemraj-Benny T, Wong SS. Covalent surface chemistry of singlewalled carbon nanotubes. Adv. Mater. 2005;17:17-29.

55. Hong H, Gao T, Cai W. Molecular imaging with single-walled carbon nanotubes. Nano Today 2009;4:252-61.

56. Gong H, Peng R, Liu Z. Carbon nanotubes for biomedical imaging: The recent advances. Adv. Drug Deliv. Rev. 2013;65:1951-63.

57. Matson ML, Wilson LJ. Nanotechnology and MRI contrast enhancement. Future Med. Chem. 2010;2:491-502.

58. Koenig SH, Kellar KE. Theory of 1/T1 and 1/T2 NMRD profiles of solutions of magnetic nanoparticles. Magn. Reson. Med. 1995;34:227-33.

59. Koenig SH, Gillis P. Transverse relaxation (1/T2) of solvent protons induced by magnetized spheres and its relevance to contrast enhancement in MRI. Invest. Radiol. 1988;23 Suppl 1:S224-8.

60. Lauffer RB. Paramagnetic metal complexes as water proton relaxation agents for NMR imaging: theory and design. Chem. Rev. 1987;87:901-27.

61. Roch A, Muller RN, Gillis P. Theory of proton relaxation induced by superparamagnetic particles. J. Chem. Phys. 1999;110:5403-11. 
62. Toth E, Helm L, Merbach AE. Relaxivity of gadolinium (III) complexes: theory and mechanism. Chem. Contrast Agents Med. Magn. Reson. Imaging 2001;45-119.

63. Sitharaman B, Kissell KR, Hartman KB, Tran LA, Baikalov A, Rusakova I, et al. Superparamagnetic gadonanotubes are high-performance MRI contrast agents. Chem. Commun. 2005;3915-7.

64. Sitharaman B, Wilson LJ. Gadonanotubes as new high-performance MRI contrast agents. Int. J. Nanomedicine 2006;1:291-5.

65. Hartman KB, Laus S, Bolskar RD, Muthupillai R, Helm L, Toth E, et al. Gadonanotubes as ultrasensitive $\mathrm{pH}$-smart probes for magnetic resonance imaging. Nano Lett. 2008;8:415-9.

66. Broome DR. Nephrogenic systemic fibrosis associated with gadolinium based contrast agents: A summary of the medical literature reporting. Eur. J. Radiol. 2008;66:230-4.

67. Tang AM, Ananta JS, Zhao H, Cisneros BT, Lam EY, Wong ST, et al. Cellular uptake and imaging studies of gadolinium-loaded single-walled carbon nanotubes as MRI contrast agents. Contrast Media Mol. Imaging 2011;6:93-9.

68. Tran LA, Krishnamurthy R, Muthupillai R, da Graça Cabreira-Hansen M, Willerson JT, Perin EC, et al. Gadonanotubes as magnetic nanolabels for stem cell detection. Biomaterials 2010;31:9482-91.

69. Tran LA, Hernández-Rivera M, Berlin AN, Zheng Y, Sampaio L, Bové C, et al. The use of gadolinium-carbon nanostructures to magnetically enhance stem cell retention for cellular cardiomyoplasty. Biomaterials 2014;35:720-6.

70. Holt BD, Law JJ, Boyer PD, Wilson LJ, Dahl KN, Islam MF. Subcellular partitioning and analysis of Gd3+-loaded ultrashort single-walled carbon nanotubes. ACS Appl. Mater. Interfaces 2015;7:14593-602.

71. Hassan AA, Chan BT-Y, Tran LA, Hartman KB, Ananta JS, Mackeyev Y, et al. Serine-derivatized gadonanotubes as magnetic nanoprobes for intracellular labeling. Contrast Media Mol. Imaging 2010;5:34-8.

72. Law JJ, Guven A, Wilson LJ. Relaxivity enhancement of aquated Tris( $\beta$ diketonate)gadolinium(III) chelates by confinement within ultrashort single-walled carbon nanotubes. Contrast Media Mol. Imaging 2014;9:409-12.

73. Ma Q, Jebb M, Tweedle MF, Wilson LJ. The gadonanotubes: structural origin of their high-performance MRI contrast agent behavior. J. Mater. Chem. B 2013;1:5791-7. 
74. Gizzatov A, Hernández-Rivera M, Keshishian V, Mackeyev Y, Law JJ, Guven A, et al. Surfactant-free Gd3+-ion-containing carbon nanotube MRI contrast agents for stem cell labeling. Nanoscale 2015;7:12085-91.

75. Swierczewska M, Rusakova I, Sitharaman B. Gadolinium and europium catalyzed growth of single-walled carbon nanotubes. Carbon 2009;47:3139-42.

76. Sitharaman B, Jacobson BD, Wadghiri YZ, Bryant H, Frank J. The magnetic, relaxometric, and optical properties of gadolinium-catalyzed single walled carbon nanotubes. J. Appl. Phys. 2013;113:134308.

77. Avti PK, Caparelli ED, Sitharaman B. Cytotoxicity, cytocompatibility, cell-labeling efficiency, and in vitro cellular magnetic resonance imaging of gadoliniumcatalyzed single-walled carbon nanotubes. J. Biomed. Mater. Res. A 2013;101:3580-91.

78. Avti PK, Talukdar Y, Sirotkin MV, Shroyer KR, Sitharaman B. Toward singlewalled carbon nanotube-gadolinium complex as advanced MRI contrast agents: Pharmacodynamics and global genomic response in small animals. J. Biomed. Mater. Res. B Appl. Biomater. 2013;101B:1039-49.

79. Marangon I, Ménard-Moyon C, Kolosnjaj-Tabi J, Béoutis ML, Lartigue L, Alloyeau $\mathrm{D}$, et al. Covalent functionalization of multi-walled carbon nanotubes with a gadolinium chelate for efficient $\mathrm{t} 1$-weighted magnetic resonance imaging. Adv. Funct. Mater. 2014;24:7173-86.

80. Weissker U, Hampel S, Leonhardt A, Büchner B. Carbon nanotubes filled with ferromagnetic materials. Materials 2010;3:4387-427.

81. Wu H, Liu G, Zhuang Y, Wu D, Zhang H, Yang H, et al. The behavior after intravenous injection in mice of multiwalled carbon nanotube / Fe3O4 hybrid MRI contrast agents. Biomaterials 2011;32:4867-76.

82. Al Faraj A, Shaik AP, Shaik AS. Magnetic single-walled carbon nanotubes as efficient drug delivery nanocarriers in breast cancer murine model: noninvasive monitoring using diffusion-weighted magnetic resonance imaging as sensitive imaging biomarker. Int. J. Nanomedicine 2014;10:157-68.

83. Al Faraj A, Shaik AS, Al Sayed B. Preferential magnetic targeting of carbon nanotubes to cancer sites: noninvasive tracking using MRI in a murine breast cancer model. Nanomed. 2015;10:931-48.

84. Liu Y, Hughes TC, Muir BW, Waddington LJ, Gengenbach TR, Easton CD, et al. Water-dispersible magnetic carbon nanotubes as T2-weighted MRI contrast agents. Biomaterials 2014;35:378-86. 
85. Liu Y, Muir BW, Waddington LJ, Hinton TM, Moffat BA, Hao X, et al. Colloidally stabilized magnetic carbon nanotubes providing mri contrast in mouse liver tumors. Biomacromolecules 2015;16:790-7.

86. Peci T, Dennis TJS, Baxendale M. Iron-filled multiwalled carbon nanotubes surface-functionalized with paramagnetic Gd (III): A candidate dual-functioning MRI contrast agent and magnetic hyperthermia structure. Carbon 2015;87:226-32.

87. Al Faraj A, Bessaad A, Cieslar K, Lacroix G, Canet-Soulas E, Crémillieux Y. Longterm follow-up of lung biodistribution and effect of instilled SWCNTs using multiscale imaging techniques. Nanotechnology 2010;21:175103.

88. Fain S, Schiebler ML, McCormack DG, Parraga G. Imaging of lung function using hyperpolarized helium-3 magnetic resonance imaging: review of current and emerging translational methods and applications. J. Magn. Reson. Imaging JMRI 2010;32:1398-408.

89. Al Faraj A, Fauvelle F, Luciani N, Lacroix G, Levy M, Crémillieux Y, et al. In vivo biodistribution and biological impact of injected carbon nanotubes using magnetic resonance techniques. Int. J. Nanomedicine 2011;6:351-61.

90. Tucker-Schwartz JM, Hong T, Colvin DC, Xu Y, Skala MC. Dual-modality photothermal optical coherence tomography and magnetic-resonance imaging of carbon nanotubes. Opt. Lett. 2012;37:872-4.

91. Vittorio O, Duce SL, Pietrabissa A, Cuschieri A. Multiwall carbon nanotubes as MRI contrast agents for tracking stem cells. Nanotechnology 2011;22:095706.

92. M. A. Lodge, E. C. Frey. Nuclear medicine imaging devices. In: Bailey DL, American Association of Physicists in Medicine, editors. Nuclear medicine physics: a handbook for teachers and students. Vienna: International Atomic Energy Agency; 2014. page 312-97.

93. Barros AB de, Tsourkas A, Saboury B, Cardoso VN, Alavi A. Emerging role of radiolabeled nanoparticles as an effective diagnostic technique. EJNMMI Res. 2012;2:39.

94. Zeglis BM, Lewis JS. A practical guide to the construction of radiometallated bioconjugates for positron emission tomography. Dalton Trans. 2011;40:6168-95.

95. Hong SY, Tobias G, Al-Jamal KT, Ballesteros B, Ali-Boucetta H, Lozano-Perez S, et al. Filled and glycosylated carbon nanotubes for in vivo radioemitter localization and imaging. Nat. Mater. 2010;9:485-90.

96. Al-Jamal KT, Nunes A, Methven L, Ali-Boucetta H, Li S, Toma FM, et al. Degree of chemical functionalization of carbon nanotubes determines tissue distribution and excretion profile. Angew. Chem. Int. Ed. 2012;51:6389-93. 
97. Wu W, Wieckowski S, Pastorin G, Benincasa M, Klumpp C, Briand J-P, et al. Targeted delivery of amphotericin B to cells by using functionalized carbon nanotubes. Angew. Chem. Int. Ed. 2005;44:6358-62.

98. Ruggiero A, Villa CH, Bander E, Rey DA, Bergkvist M, Batt CA, et al. Paradoxical glomerular filtration of carbon nanotubes. Proc. Natl. Acad. Sci. 2010;107:1236974.

99. Lacerda L, Herrero MA, Venner K, Bianco A, Prato M, Kostarelos K. Carbonnanotube shape and individualization critical for renal xxcretion. Small 2008;4:1130-2.

100. Ruggiero A, Villa CH, Holland JP, Sprinkle SR, May C, Lewis JS, et al. Imaging and treating tumor vasculature with targeted radiolabeled carbon nanotubes. Int. J. Nanomedicine 2010;5:783-802.

101. Huang X, Zhang F, Sun X, Choi K-Y, Niu G, Zhang G, et al. The genotypedependent influence of functionalized multiwalled carbon nanotubes on fetal development. Biomaterials 2014;35:856-65.

102. Liu Z, Cai W, He L, Nakayama N, Chen K, Sun X, et al. In vivo biodistribution and highly efficient tumour targeting of carbon nanotubes in mice. Nat. Nanotechnol. 2007;2:47-52.

103. Yu SB, Watson AD. Metal-based X-ray contrast media. Chem. Rev. 1999;99:235378.

104. Rabin O, Manuel Perez J, Grimm J, Wojtkiewicz G, Weissleder R. An X-ray computed tomography imaging agent based on long-circulating bismuth sulphide nanoparticles. Nat. Mater. 2006;5:118-22.

105. Kinsella JM, Jimenez RE, Karmali PP, Rush AM, Kotamraju VR, Gianneschi NC, et al. X-ray computed tomography imaging of breast cancer by using targeted peptide-labeled bismuth sulfide nanoparticles. Angew. Chem. Int. Ed Engl. 2011;50:12308-11.

106. Popovtzer R, Agrawal A, Kotov NA, Popovtzer A, Balter J, Carey TE, et al. Targeted gold nanoparticles enable molecular CT imaging of cancer. Nano Lett. 2008;8:4593-6.

107. Hainfeld JF, Slatkin DN, Focella TM, Smilowitz HM. Gold nanoparticles: a new Xray contrast agent. Br. J. Radiol. 2006;79:248-53.

108. Ashcroft JM, Hartman KB, Kissell KR, Mackeyev Y, Pheasant S, Young S, et al. Single-molecule I2@US-tube nanocapsules: a new X-ray contrast-agent design. Adv. Mater. 2007;19:573-6. 
109. Gordon MF, Abrams RI, Rubin DB, Barr WB, Correa DD. Bismuth subsalicylate toxicity as a cause of prolonged encephalopathy with myoclonus. Mov. Disord. 1995;10:220-2.

110. Reynolds PT, Abalos KC, Hopp J, Williams ME. Bismuth toxicity: a rare cause of neurologic dysfunction. Int. J. Clin. Med. 2012;03:46-8.

111. Rivera EJ, Tran LA, Hernández-Rivera M, Yoon D, Mikos AG, Rusakova IA, et al. Bismuth@US-tubes as a potential contrast agent for X-ray imaging applications. J. Mater. Chem. B 2013;1:4792-800.

112. Frangioni JV, Hajjar RJ. In Vivo Tracking of stem cells for clinical trials in cardiovascular disease. Circulation 2004;110:3378-83.

113. Arifin DR, Long CM, Gilad AA, Alric C, Roux S, Tillement O, et al. Trimodal gadolinium-gold microcapsules containing pancreatic islet cells restore normoglycemia in diabetic mice and can be tracked by using US, CT, and positivecontrast MR imaging. Radiology 2011;260:790-8.

114. Barnett BP, Ruiz-Cabello J, Hota P, Liddell R, Walczak P, Howland V, et al. Fluorocapsules for improved function, immunoprotection, and visualization of cellular therapeutics with MR, US, and CT imaging. Radiology 2011;258:182-91.

115. Barnett BP, Kraitchman DL, Lauzon C, Magee CA, Walczak P, Gilson WD, et al. Radiopaque alginate microcapsules for $\mathrm{X}$-ray visualization and immunoprotection of cellular therapeutics. Mol. Pharm. 2006;3:531-8.

116. Louie A. Multimodality imaging probes: design and challenges. Chem. Rev. 2010;110:3146-95.

117. Hu Z, Yang W, Liu H, Wang K, Bao C, Song T, et al. From PET/CT to PET/MRI: Advances in instrumentation and clinical applications. Mol. Pharm. 2014;11:3798809.

118. Cisneros BT, Law JJ, Matson ML, Azhdarinia A, Sevick-Muraca EM, Wilson LJ. Stable confinement of positron emission tomography and magnetic resonance agents within carbon nanotubes for bimodal imaging. Nanomed. 2014;9:2499-509.

119. Wang JT-W, Cabana L, Bourgognon M, Kafa H, Protti A, Venner K, et al. Magnetically decorated multiwalled carbon nanotubes as dual MRI and SPECT contrast agents. Adv. Funct. Mater. 2014;24:1880-94.

120. Al Faraj A, Shaik AS, Al Sayed B, Halwani R, Al Jammaz I. Specific targeting and noninvasive imaging of breast cancer stem cells using single-walled carbon nanotubes as novel multimodality nanoprobes. Nanomed. 2015;11:31-46. 
121. Zhao X, Liu R. Recent progress and perspectives on the toxicity of carbon nanotubes at organism, organ, cell, and biomacromolecule levels. Environ. Int. 2012;40:244-55.

122. Liu Y, Zhao Y, Sun B, Chen C. Understanding the toxicity of carbon nanotubes. Acc. Chem. Res. 2013;46:702-13.

123. Wang J, Xu Y, Yang Z, Huang R, Chen J, Wang R, et al. Toxicity of carbon nanotubes. Curr. Drug Metab. 2013;14:891-9.

124. Allen BL, Kichambare PD, Gou P, Vlasova II, Kapralov AA, Konduru N, et al. Biodegradation of single-walled carbon nanotubes through enzymatic catalysis. Nano Lett. 2008;8:3899-903.

125. Kagan VE, Konduru NV, Feng W, Allen BL, Conroy J, Volkov Y, et al. Carbon nanotubes degraded by neutrophil myeloperoxidase induce less pulmonary inflammation. Nat. Nanotechnol. 2010;5:354-9.

126. Kotchey GP, Zhao Y, Kagan VE, Star A. Peroxidase-mediated biodegradation of carbon nanotubes in vitro and in vivo. Adv. Drug Deliv. Rev. 2013;65:1921-32. 